Case Report

\title{
Anesthetic Management of a Surgical Patient with Chronic Renal Tubular Acidosis Complicated by Subclinical Hypothyroidism
}

\author{
Hiroe Yoshioka, Haruyuki Yamazaki, Rie Yasumura, Kosuke Wada, and Yoshiro Kobayashi \\ Department of Anesthesiology, National Hospital Organization Tokyo Medical Center, 2-5-1 Higashigaoka, Meguro-ku, \\ Tokyo 152-8902, Japan \\ Correspondence should be addressed to Hiroe Yoshioka; hiroe_y_0614@hotmail.co.jp
}

Received 2 April 2016; Revised 15 July 2016; Accepted 14 August 2016

Academic Editor: Renato Santiago Gomez

Copyright (C) 2016 Hiroe Yoshioka et al. This is an open access article distributed under the Creative Commons Attribution License, which permits unrestricted use, distribution, and reproduction in any medium, provided the original work is properly cited.

\begin{abstract}
A 53-year-old man with chronic renal tubular acidosis and subclinical hypothyroidism underwent lower leg amputation surgery under general anesthesia. Perioperative acid-base management in such patients poses many difficulties because both pathophysiologies have the potential to complicate the interpretation of capnometry and arterial blood gas analysis data; inappropriate correction of chronic metabolic acidosis may lead to postoperative respiratory deterioration. We discuss the management of perioperative acidosis in order to achieve successful weaning from mechanical ventilation and promise a complete recovery from anesthesia.
\end{abstract}

\section{Introduction}

Metabolic acidosis is categorized clinically as high or normal anion gap based on the presence or absence of unmeasured anions in serum. Renal tubular acidosis (RTA) is characterized by normal anion-gap metabolic acidosis, originating from excessive urinary loss of bicarbonate or defective urinary acidification [1]. Therefore, unlike high anion-gap acidoses (e.g., lactic acidosis or ketoacidosis), RTA must be treated with administration of sodium bicarbonate. However, perioperative acid-base management in such cases poses many difficulties because the total carbon dioxide $\left(\mathrm{CO}_{2}\right)$ content in blood as well as actual blood $\mathrm{pH}$ must be fully taken into consideration for successful weaning from mechanical ventilation. In addition, thyroid function is associated with basal metabolic rate and $\mathrm{CO}_{2}$ production; thus, subclinical hypothyroidism presents specific challenges for anesthesiologists.

This case highlights the perioperative acid-base management of a patient who has suffered from untreated chronic RTA complicated by subclinical hypothyroidism while undergoing lower leg amputation surgery under general anesthesia. We report this case because the anesthetic management of similar cases has rarely been reported; in addition, there has been no prior report detailing the management of perioperative acidosis, which is the focal point of this case.

\section{Case Presentation}

A 53-year-old man (height: $167 \mathrm{~cm}$; weight: $48 \mathrm{~kg}$ ) who presented difficulty in walking due to severe pain in his lower leg was brought to our hospital by an ambulance. The patient had a prior history of chronic kidney disease, arteriosclerosis obliterans, and insulin-dependent diabetes mellitus. Physical and laboratory examination revealed ulcerative formations in the left lower leg and severe metabolic acidosis (Table 1). An intravenous subsequently oral administration of sodium bicarbonate resulted in marked improvement of the acidosis. Upon detailed examination, polyarteritis nodosa was strongly suspected as the etiology of the refractory ulcer in the lower leg; simultaneously, RTA type 4 was diagnosed based on a prior history of hyperkalemia and diabetes, accompanying a low serum aldosterone level.

For suspected pathophysiology, a $10 \mathrm{mg}$ daily oral dose of prednisolone had been administered for about 2 months but his ulcerative lesions deteriorated; therefore, the patient was 
TABLE 1: Perioperative blood gas analysis.

\begin{tabular}{lcccc}
\hline & On admission & Preoperative & Immediately after intubation & Postoperative \\
\hline $\mathrm{pH}$ & 7.031 & 7.345 & 7.286 & 34.4 \\
$\mathrm{PaCO}_{2}(\mathrm{mmHg})$ & 13.6 & 27.7 & 16.0 & 37.1 \\
$\mathrm{HCO}_{3}{ }^{-}(\mathrm{mmol} / \mathrm{L})$ & 3.5 & 14.8 & -9.7 & 19.8 \\
$\mathrm{BE}(\mathrm{mmol} / \mathrm{L})$ & -25.3 & -10.0 & 4.8 & -5.4 \\
AnGap $(\mathrm{mmol} / \mathrm{L})$ & 18.1 & 3.6 & - & 2.7 \\
Lactate $(\mathrm{mg} / \mathrm{dL})$ & 15.4 & 17.4 & - \\
\hline
\end{tabular}

AnGap: anion gap; $\mathrm{BE}$ : base excess; $\mathrm{HCO}_{3}{ }^{-}$: bicarbonate; $\mathrm{PaCO}_{2}$ : arterial carbon dioxide partial pressure.

TABLE 2: Preoperative laboratory test values.

\begin{tabular}{lc}
\hline & Test value (normal range) \\
\hline HGB $(\mathrm{g} / \mathrm{dL})$ & $7.1(13.5-17.0)$ \\
PLT $\left(\times 10^{9} / \mathrm{L}\right)$ & $59(150-350)$ \\
BUN $(\mathrm{mg} / \mathrm{dL})$ & $32.7(8.0-22.0)$ \\
Cre $(\mathrm{mg} / \mathrm{dL})$ & $2.6(0.6-1.1)$ \\
TP $(\mathrm{g} / \mathrm{dL})$ & $4.6(6.3-8.2)$ \\
Alb $(\mathrm{g} / \mathrm{dL})$ & $2.1(3.5-5.2)$ \\
Na $(\mathrm{Mmol} / \mathrm{L})$ & $128(138-146)$ \\
$\mathrm{K}(\mathrm{Mmol} / \mathrm{L})$ & $5.3(3.6-4.9)$ \\
$\mathrm{Cl}(\mathrm{Mmol} / \mathrm{L})$ & $106(99-109)$ \\
PRA $(\mathrm{ng} / \mathrm{mL} / \mathrm{h})$ & $0.3(0.2-2.7)$ \\
PAC $(\mathrm{pg} / \mathrm{mL})$ & $13(36-240)$ \\
TSH $(\mathrm{U} / \mathrm{dL})$ & $6.17(0.3-4.5)$ \\
T3 $(\mathrm{pg} / \mathrm{mL})$ & $1.2(2.0-4.5)$ \\
T4 $(\mathrm{ng} / \mathrm{dL})$ & $1.1(0.7-1.8)$ \\
\hline
\end{tabular}

Alb: albumin; BUN: blood urea nitrogen; Cl: chloride; Cre: creatinine; HGB: hemoglobin; K: potassium; Na: sodium; PAC: plasma aldosterone concentration; PRA: plasma renin activity; TP: total protein; TSH: thyroidstimulating hormone; T3: triiodothyronine; T4: thyroxine.

scheduled for lower leg amputation surgery about 3 months after admission.

Preoperative laboratory tests (Table 2) revealed impaired renal function and hyperkalemia, while those findings were compatible with RTA type 4 . With regard to endocrine function, we suspected subclinical hypothyroidism due to reduced plasma triiodothyronine (T3) levels and elevated thyroidstimulating hormone (TSH). Blood gas analysis showed severe metabolic acidosis accompanied by normal anion gap corrected for albumin and compensatory respiratory alkalosis (Table 1), because the oral sodium bicarbonate therapy had been discontinued 2 months before the surgery. Despite severe metabolic acidosis, the history and physical examination did not indicate any obvious evidence of hyperventilation. The patient had a body temperature of $36.4^{\circ} \mathrm{C}$, blood pressure of $121 / 73 \mathrm{mmHg}$, a heart rate of 89 beats per minute (bpm), a respiratory rate of 10 breaths per minute, and an oxygen saturation level of $98 \%$ (room air); chest radiography and electrocardiogram examinations revealed no abnormalities.

General anesthesia was scheduled instead of regional anesthesia because of low platelet count. Oral prednisolone $(10 \mathrm{mg} /$ day) was continued until the day of the surgery.
Preoperative values of blood pressure, heart rate, respiratory rate, and body temperature were almost within normal ranges: $142 / 91 \mathrm{mmHg}, 84 \mathrm{bpm}, 10$ breaths per minute, and $35.8^{\circ} \mathrm{C}$, respectively. Endotracheal intubation under general anesthesia was provided with intravenous induction of $50 \mu \mathrm{g}$ fentanyl, $70 \mathrm{mg}$ propofol, and $40 \mathrm{mg}$ rocuronium; and anesthesia was maintained by $1.2-1.8 \%$ sevoflurane with intermittent intravenous administration of fentanyl. The total amount of fentanyl was $250 \mu \mathrm{g}$ during operation. The end tidal $\mathrm{CO}_{2}\left(\mathrm{ETCO}_{2}\right)$ level of the patient was $22 \mathrm{mmHg}$ immediately after intubation; then his minute volume was set at $3 \mathrm{~L} / \mathrm{min}$. However, the blood gas analysis revealed that the arterial carbon dioxide partial pressure $\left(\mathrm{PaCO}_{2}\right)$ of the patient was within the normal range (Table 1). The frequency of ventilation was subsequently adjusted to and maintained at a rate of $3-3.5 \mathrm{~L} / \mathrm{min}$, in order to ensure that the $\mathrm{PaCO}_{2}$ remained within the normal range. During this time, $\mathrm{ETCO}_{2}$ levels were 22-29 $\mathrm{mmHg}$.

The total time of surgery was $1 \mathrm{~h}$ and $48 \mathrm{~min} ; 1250 \mathrm{~mL}$ of crystalloid solution (normal saline and hypotonic solution which contains no potassium), $280 \mathrm{~mL}$ of red blood cell transfusion, and $100 \mathrm{~mL}$ of $8.4 \%$ sodium bicarbonate were administered during the surgery. The total blood loss and urine volume were determined to be $170 \mathrm{~mL}$ and $150 \mathrm{~mL}$, respectively. Although the patient continued to exhibit mild signs of metabolic acidosis upon completion of surgery (Table 1), this did not appear to impact his circulatory condition. A chest radiograph taken upon completion of surgery revealed a small amount of bilateral pleural effusion. The patient was given a muscle relaxant antagonist $(200 \mathrm{mg}$ of sugammadex) after awakening and was extubated after a spontaneous breathing trial. There was no appreciable event during the surgery, except a red blood cell transfusion. No subsequent problems related to hyperventilation or apnea were observed, and the patient was sent back to his room without incident.

\section{Discussion}

RTA is classified into three types based on pathophysiology. Among them, RTA type 4 is characterized by distal tubular aldosterone resistance or aldosterone deficiency, resulting in hyperkalemia and onset of metabolic acidosis [1]. RTA type 4 is usually asymptomatic with only mild acidosis but can be occasionally accompanied by life-threatening electrolyte disturbances and severe decrease in bicarbonate concentration. In addition, its clinical course tends to be prolonged 
and thus complicated as with this case. Therefore, rather than actual blood $\mathrm{pH}$, time-dependent changes in contained $\mathrm{CO}_{2}$ in the whole body should be taken into consideration for successful weaning from mechanical ventilation when perioperative corrective treatment is performed.

Literature reviews of anesthetic management of patients with severe acute metabolic acidosis have focused on the maintenance of adequate blood pressure and tissue perfusion. However, in chronic cases, anesthesiologists should give attention to intraoperative acid-base status in order to ensure adequate spontaneous breathing immediately after surgery.

In general, respiratory drive is stimulated by low $\mathrm{pH}$, particularly in patients with chronic metabolic acidosis. Therefore, any arterial $\mathrm{pH}$, which is higher than preoperative value, can be associated with a higher risk for postoperative hypoventilation to various degrees, even if normal acid-base balance without hypercapnia has been achieved at the time of weaning from mechanical ventilation. Rapid or excessive correction of chronic metabolic acidosis during surgery leads to either life-threatening hypoventilation or sudden onset of apnea [2].

With regard to correction of acidosis, there is no conclusive evidence to support bicarbonate administration to surgical patients with chronic metabolic acidosis. In contrast, patients of RTA type 4 need administration of bicarbonate at a daily rate of $1.5-2 \mathrm{mmol} / \mathrm{kg}$ [1]; nevertheless, the dose and rate of perioperative bicarbonate administration remain controversial in particular cases.

In general, severe metabolic acidosis with arterial $\mathrm{pH}<$ 7.2 is associated with higher mortality in critically ill patients [3]; therefore, we adjusted the ventilator settings and bicarbonate administration to maintain arterial $\mathrm{pH}$ at a value simultaneously less than the preoperative value and higher than 7.2 along with normocapnia.

On the other hand, the clinical picture of this case was remarkable in the light of perioperative $\mathrm{PaCO}_{2}$ level when compared to that of most patients with severe metabolic acidosis.

Firstly, although the preoperative $\mathrm{PaCO}_{2}$ of the patient was extremely low $(27.7 \mathrm{mmHg})$, which seems to be respiratory overcompensation, no obvious signs of deep breathing or hyperventilation were observed. Secondly, despite the adjustment of the minute volume in order to bring the $\mathrm{PaCO}_{2}$ level within the normal range, low minute volume was required for this patient. For comparison, the minute volume and the $\mathrm{PaCO}_{2}$ level were assessed in other surgical patients without metabolic acid-base disorders (Table 3). The minute volume and the $\mathrm{PaCO}_{2}$ level exhibited by the patient in this case were lower than the group average. Based on these observations, we speculated that any underlying pathophysiologies might lead to a decrease in $\mathrm{PaCO}_{2}$ without an increase in alveolar ventilation.

Specifically, the body equilibrium of RTA patients is known to shift to the left as follows: $\mathrm{H}^{+}+\mathrm{HCO}_{3}{ }^{-} \rightleftarrows$ $\mathrm{H}_{2} \mathrm{CO}_{3} \rightleftarrows \mathrm{H}_{2} \mathrm{O}+\mathrm{CO}_{2}$; as such, if the bicarbonate level is not replenished, the internal $\mathrm{CO}_{2}$ level will be depleted, resulting in a decline in $\mathrm{PaCO}_{2}$.

As another speculation, subclinical hypothyroidism may possibly lead to decreased $\mathrm{CO}_{2}$ production in the body
TABLE 3: Minute volume and $\mathrm{PaCO}_{2}$ levels of 29 male patients (aged 48-90) subjected to nonlaparoscopic surgery.

\begin{tabular}{lc}
\hline & Mean (SD) \\
\hline Age (years) & $74.0(11.2)$ \\
Height $(\mathrm{cm})$ & $165.0(5.2)$ \\
Weight $(\mathrm{kg})$ & $48.7(2.2)$ \\
Minute volume (L/min) & $4.8(1.0)$ \\
$\mathrm{PaCO}_{2}(\mathrm{mmHg})$ & $39.1(5.0)$ \\
\hline
\end{tabular}

$\mathrm{PaCO}_{2}$ : arterial carbon dioxide partial pressure.

because decreased thyroid function is associated with diminished basal metabolic rate, thus resulting in reduced tissue $\mathrm{CO}_{2}$ production [4]; similarly, subclinical hypothyroidism is reported to induce a decrease in resting energy expenditure [5].

Definitely, subclinical hypothyroidism and RTA type 4 have the potential to complicate the reading and interpretation of capnometry and $\mathrm{PaCO}_{2}$ measurements.

In order to avoid postoperative respiratory deterioration in patients with chronic metabolic acidosis, anesthesiologists should give basic consideration to the previously documented pitfalls: type of anesthesia, dose of opioids used in combination, methods of postoperative pain management, and body temperature of the patient. Besides, perioperative acid-base management on the basis of the abovementioned goal of $\mathrm{pH}$ and $\mathrm{PaCO}_{2}$ will probably determine success of weaning from mechanical ventilation and promise a complete recovery from anesthesia in patients with RTA complicated by subclinical hypothyroidism. Given that hemodynamic stability has already been achieved in patients suffering from long-term preoperative exposure to RTA with low serum bicarbonate concentration, the main anesthetic concerns should include the dose and rate of bicarbonate administration tailored according to the patient's usual acid-base balance and preoperative respiratory status: $\mathrm{PaCO}_{2}$ levels, the minute volume, and the presence of signs of deep breathing or hyperventilation.

\section{Ethical Approval}

Written informed consent from the patient was not obtained because of the patient's death. The authors received permission from the Institutional Review Board of National Hospital Organization Tokyo Medical Center to publish this case report.

\section{Competing Interests}

The authors declare that there is no conflict of interests regarding the publication of this paper.

\section{References}

[1] J. R. Soriano, "Renal tubular acidosis: the clinical entity," Journal of the American Society of Nephrology, vol. 13, no. 8, pp. 21602170, 2002. 
[2] D. Chan, S. Thong, and O. Ng, "Postoperative apnoea in an adult patient after rapid correction of metabolic acidosis," OA Case Reports, vol. 3, no. 2, article 16, 2014.

[3] B. Jung, T. Rimmele, C. Le Goff et al., "Severe metabolic or mixed acidemia on intensive care unit admission: incidence, prognosis and administration of buffer therapy. A prospective, multiple-center study," Critical Care, vol. 15, no. 5, article R238, 2011.

[4] H. T. Lee and M. Levine, "Acute respiratory alkalosis associated with low minute ventilation in a patient with severe hypothyroidism," Canadian Journal of Anaesthesia, vol. 46, no. 2, pp. 185-189, 1999.

[5] M. Tagliaferri, M. E. Berselli, G. Calò et al., "Subclinical hypothyroidism in obese patients: relation to resting energy expenditure, serum leptin, body composition, and lipid profile," Obesity Research, vol. 9, no. 3, pp. 196-201, 2001. 


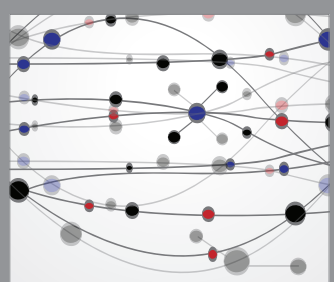

The Scientific World Journal
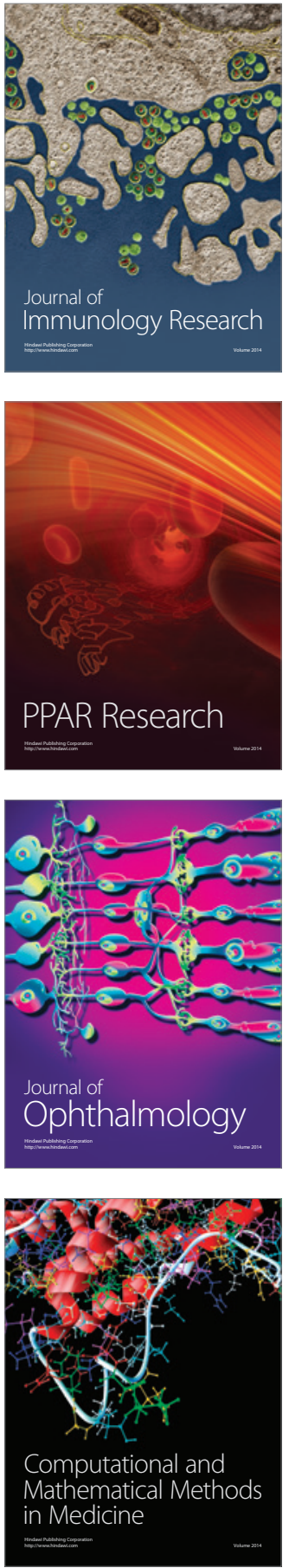

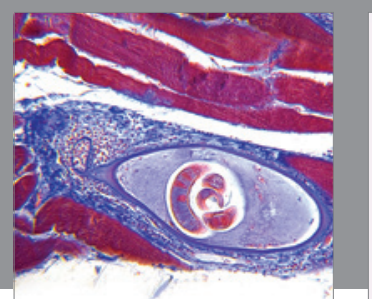

Gastroenterology Research and Practice

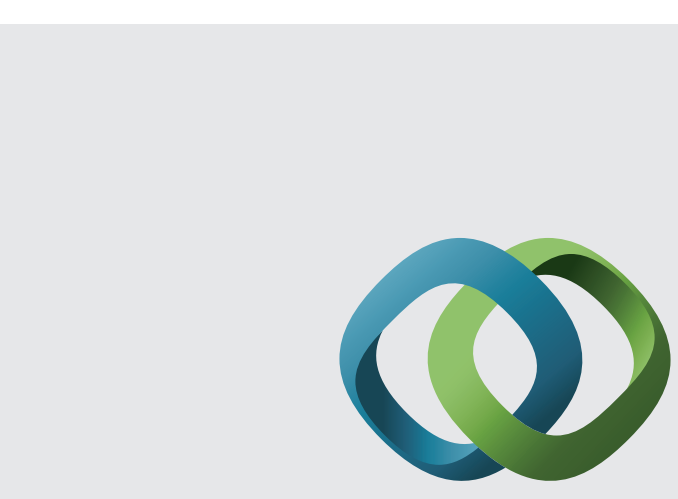

\section{Hindawi}

Submit your manuscripts at

http://www.hindawi.com
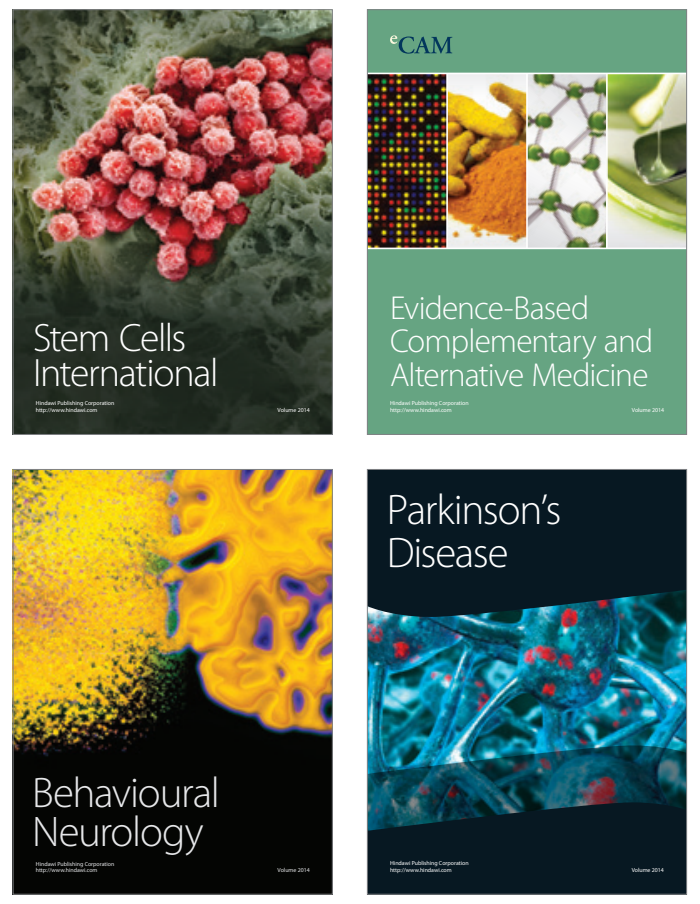
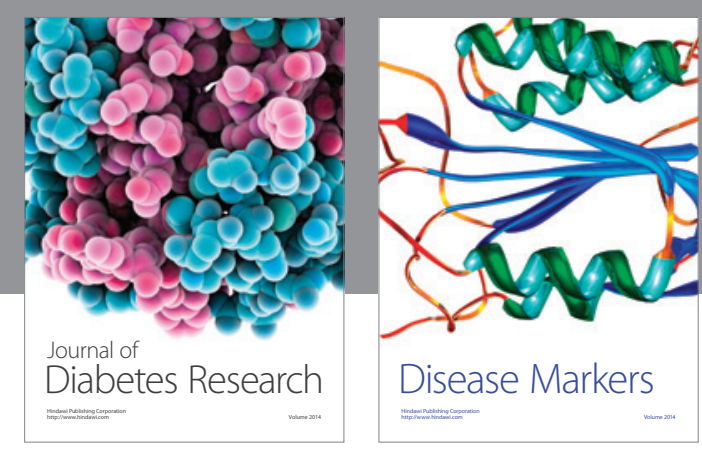

Disease Markers
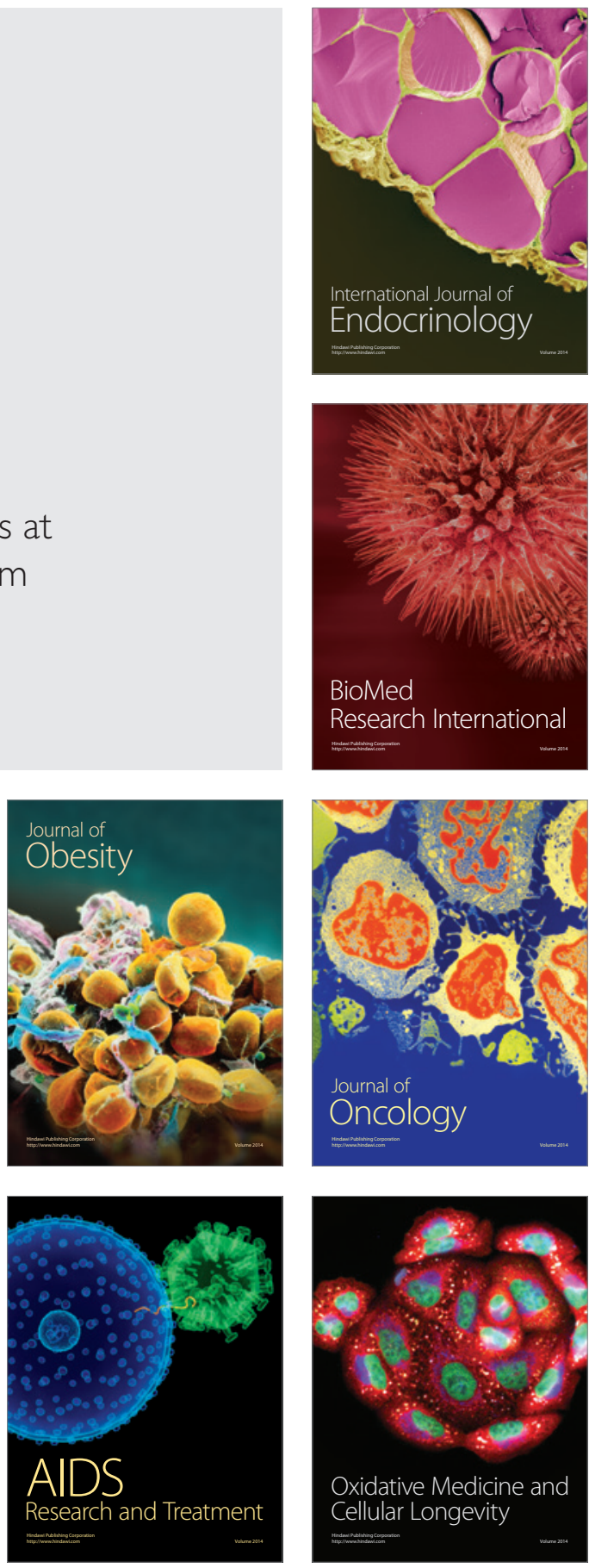